Wilfrid Laurier University

Scholars Commons @ Laurier

Lyle S. Hallman Social Work Faculty

Publications

Lyle S. Hallman Faculty of Social Work

6-2018

\title{
Exploratory study of the use of community treatment orders with clients of an Ontario ACT team
}

\author{
Magnus Mfoafo-M'Carthy \\ Wilfrid Laurier University, mmfoafomcarthy@wlu.ca \\ Cara Grosset \\ Wilfrid Laurier University, cgrosset@wlu.ca \\ Carol Stalker \\ Wilfrid Laurier University, cstalker@wlu.ca \\ Irene Dullaart \\ Homewood Health Centre, IDullaart@homewoodhealth.com \\ Linda McColl Dr. \\ Homewood Health Centre, McCoLind@homewood.org
}

Follow this and additional works at: https://scholars.wlu.ca/scwk_faculty

Part of the Mental and Social Health Commons, Mental Disorders Commons, and the Social Work Commons

\section{Recommended Citation}

Magnus Mfoafo-M'Carthy, Cara Grosset, Carol Stalker, Irene Dullaart \& Linda McColl (2018): Exploratory study of the use of community treatment orders with clients of an Ontario ACT team, Social Work in Mental Health, DOI: 10.1080/15332985.2018.1476283

This Article is brought to you for free and open access by the Lyle S. Hallman Faculty of Social Work at Scholars Commons @ Laurier. It has been accepted for inclusion in Lyle S. Hallman Social Work Faculty Publications by an authorized administrator of Scholars Commons @ Laurier. For more information, please contact scholarscommons@wlu.ca. 
Sacial Work
Inimintilifatil

Journal

Social Work in Mental Health >

Latest Articles
Enter keywords, authors, DOI etc

This Journal

Advanced search

\section{1}

0

0

Altmetric

In this article $x$

Original Articles

\title{
Exploratory study of the use of community treatment orders with clients of an Ontario ACT team
}

Magnus Mfoafo-M'Carthy $\boldsymbol{\nabla}$, PhD, Cara Grosset, MSW, Carol Stalker, PhD, Irene Dullaart, MSW, RSW \& Linda McColl , MD., FRCPC Received 05 Sep 2017, Accepted 10 May 2018, Accepted author version posted online: 23 May 2018

SS Download citation

(2ttps://doi.org/10.1080/15332985.2018.1476283

(M) Check for updates

\begin{tabular}{|c|c|c|c|}
\hline 算 Full Article & 0 Figures \& data & E References & SS Citations \\
\hline
\end{tabular}

- Accepted author version

\begin{abstract}
Community Treatment Orders (CTOs) have raised questions about coercion, lack of autonomy and effectiveness in reducing hospitalizations and improving service users' quality of life. This study examined the experiences of clients and clinicians when CTOs are used in combination with Assertive Community Treatment (ACT) in a recovery oriented approach. Eleven clients who were or had previously been on a CTO and eight ACT clinicians were interviewed. Although most clients had negative feelings about CTOs, some acknowledged their lives had improved. Clinicians reported that the decision to employ a CTO is sometimes debated within the team but they agreed that combining CTOs and ACT resulted in regular access to mental health supports, fewer hospitalizations and overall improvement of quality of life for their clients.
\end{abstract}




\section{Introduction Disclaimer}

Literature review

Methodology

Findings

Discussion

Conclusion

References
As a service to authors and researchers we are providing this version of an accepted manuscript (AM). Copyediting, typesetting, and review of the resulting proofs will be undertaken on this manuscript before final publication of the Version of Record (VoR). During production and prepress, errors may be discovered which could affect the content, and all legal disclaimers that apply to the journal relate to these versions also.

\section{Introduction}

Community Treatment Orders (CTOs) were introduced in 2000 in Ontario to "provide a person who suffers from a serious mental disorder with a comprehensive plan of community-based treatment or care and supervision that is less restrictive than being detained in a psychiatric facility" (Ontario Mental Health Act 33.1(3)). Though CTOs have generated considerable controversy (Mfoafo-M'Carthy \& Williams, $\boldsymbol{\theta}$ 2010), research has supported the effectiveness of CTOs with respect to reduced hospitalizations and violent behavior, and improved client quality of life (O'Brien, Farrell, \& Faulkner, E 2009; O'Reilly et al., E 2009). Despite the controversy of CTOs, service users tend to have contradictory feelings about being on a CTO with respect to feeling coerced, stigmatized, and experiencing a lack of control over their lives, while acknowledging some benefits associated with the CTO (Gault, $\boldsymbol{\theta}$ 2009; O'Reilly, Keegan, Corring, Shrikhande, \& Natarajan, E 2006).

Assertive Community Treatment Teams (ACTTs) are an evidence-based approach to supporting individuals with serious mental disorders in the community. Research supports the efficacy of the ACTT model in increasing patient interaction with mental health clinicians in the community, housing stability, subjective sense of quality of life, and 
reducing symptoms for clients (Bond, Drake, Muesser, \& Latimer, 2001; Tibbo, Chue, \& Wright, 1999). Exploring research on CTOs and ACTT, has uncovered only one study that has examined the use of CTOs in combination with support from an ACTT. This study was conducted in the U.S. and used administrative data to compare service users on court orders for Assisted Outpatient Treatment (AOT) (the equivalent of a (TO) who also received ACTT services with service users on an AOT who did not receive ACTT services (Swartz et al., $\boldsymbol{\theta}$ 2010). This study found the addition of the court order reduced the likelihood of hospitalizations by $43 \%$ and increased the likelihood of high engagement with services as rated by case managers. However, the perspectives of the clients and service providers were not reported.

When the experiences of clinicians and clients are sought through engagement in research there is an increased potential to obtain data more descriptive of the impact of CTO's. For example, a recent Ontario study found ACTT staff who rated themselves higher on recovery-oriented service provision tended to have more promising client outcomes (Kidd et al., $\boldsymbol{\theta}$ 2011). This raises the question of how ACTTS reconcile the use of CTOs, which can be viewed as a means of coercive treatment, with the recovery principles of client empowerment, involvement in decisions, and choice, as articulated by the Ontario Program Standards for ACT teams (Government of Ontario, Ministry of Health and Long-term Care, 2005).

This is the first Canadian study to examine the perspectives of clients who are or have been on a CTO while they are/were simultaneously service users of an ACTT. We also explored the perspectives and rationales of the ACTT service providers regarding the use of CTOs with their service users. The ACTT that is the focus of this study is located in a medium sized urban community in Southwestern Ontario (Guelph). 


\section{Objectives of the study}

The following were the objectives of the study:

1) To increase knowledge about the experiences and perceptions regarding Community Treatment Orders (CTOs) of clients receiving treatment from the Guelph ACTT who were, or had previously been placed on CTOs; 2) To increase knowledge about conditions and circumstances that contribute to decisions to place ACTT clients on CTOs; and, 3) To increase knowledge about the experiences and perspectives of the ACTT service providers regarding the rationale and effects of these decisions.

\section{Literature review}

Ontario introduced CTOs as a prescribed treatment option for individuals with serious mental illness in 2000 (O'Brien et al., 1 2009). Ontario's legislation requires that the service users, or a substitute decision maker (SDM) if the service user is not capable, consents to the CTO. However, Gray and O'Reilly ( $(\boldsymbol{\theta}$ 2005) state, the "voluntary" nature of the agreement, only applies to a relatively few individuals as the majority are incapable of consenting (p.19). This is one aspect which lends itself to the argument that CTOs are coercive in nature.

Much of the research on CTOs or mandated treatment has been done in the United States and Australia, and this reveals mixed findings and a spirited debate. A review of the effectiveness of these orders in eight U.S. states concluded that most treatment providers do not have the resources needed to provide the high level of supervision required in order to promote client success (Ridgely, Borum \& Petrila, 2001). A group of researchers in Western Australia have been quite vocal in questioning the effectiveness of compulsory care and their findings from randomized controlled trials indicate no significant difference between 
compulsory and non-compulsory care with respect to social functioning and quality of life; however, those on mandated treatment were less likely to be victims of violence (Kisely \& Campbell, ש 2014, p. 3). No randomized controlled trials have been conducted in Canada probably because of ethical and legal issues related to research principles and professional standards of care and ethics. (Kisely et al., E 2013). Thus, comparisons between outcomes for people with serious mental illness who receive CTO and ACTT services and those who do not has not been undertaken (in Canada).

Debate exists around how to measure the effectiveness of CTOs . Some studies have used reduction in the number of hospitalizations as the criteria, while others have argued for reduced length or reduced frequency of hospitalizations, and other quality of life criteria (Dye, Dannaram, Loynes, \& Dickenson, 9 2012; Nakhost, Perry, \& Frank, $\theta$ 2012; Schwartz et al., 2 2010). Several studies have shown CTOs to be useful for service users in multiple facets of life, such as: improved contact with mental health services; a reduction in violent behavior, being victimized, mortality rates, and substance abuse; and, increased use of community services, increased likelihood of employment, and improved housing stability while on a CTO (O'Brien \& Farrell, 2005; Kisely et al., E 2013; O’Brien et al., $\boldsymbol{\theta}$ 2009; O'Reilly et al., $\boldsymbol{\theta}$ 2009).

In several countries, research indicates service users tend to have ambivalent feelings about being on a CTO (Schwartz et al., $\boldsymbol{\theta}$ 2010). Service users in the U.K. felt "reluctant to comply" with the treatment and level of satisfaction varied (Gault, E 2009; p. 504; Fahy, Javaid, \& Best, ש 2013). In Saskatchewan, Canada, O'Reilly et al. ( "most experienced some degree of coercion", whereas many believed it provided "necessary structure in their lives" (p. 516). In Scotland, Ridley and Hunter ( $\boldsymbol{\theta}$ 2013) concluded the focus was on service user compliance with a medication order, although some users saw other advantages. A study 
by Schwartz et al. ( 2010 ) is the only published study that has explored service users' experiences of CTOs in Ontario. They found service users experiences were similar to those reported in other countries, but their participants were less concerned about the CTO itself and more concerned "about the labels, control and discrimination associated with severe mental illness" (p. 1).

Further to the experience of being labelled and discriminated against, ervice providers in Australia were concerned about the stigma, loss of freedom and control over life, restrictions, lacking choice in treatment, being disempowered, and having less life opportunities that clients were articulating (Brophy \& Ring, $\boldsymbol{\theta}$ 2004). Gault (早 2009) articulates that when professionals "see risk rather than people" (p. 511) and fail to work with clients respectfully and collaboratively, clients often resist through noncompliance leading to more coercive measures.

Service users' views of mandated community treatment could also be affected by their understanding of what the order means. Fahy et al. ( $\boldsymbol{\theta}$ 2013) found that most of their U.K patients understood supervised community treatment was associated with earlier discharge from hospital but many did not feel involved in the planning process, and misunderstood their legal rights and right to appeal. The researchers recommended patients' rights be revisited at regular frequent intervals. In Ontario, the maximum duration of a CTO is six months and is renewable for another six months. Hearings are mandatory every second time the CTO is renewed, that is after the client has been on it for a year.

A CTO does not always guarantee a client access to an ACT team, as clients with a CTO can also be under the care of only their physician. ACT has been described as "a model of service delivery that provides continuous services to promote the community adjustments of persons with severe mental illness and high service usage" (Krupa et al., $\boldsymbol{\theta}$ 2004, 
p. 115). ACT teams provide many services for individuals receiving treatment, those with a CTO and many without a CTO: counselling; assistance with finances, housing, paperwork, and finding appropriate opportunities for work; medication support; health promotion; family involvement; and, improving daily living skills (Phillips et al., ש 2001). Individualized services are offered $24 / 7$ with staff ratio of 1:10 (Phillips et al., $\boldsymbol{\theta}$ 2001). ACT teams are intended to be multi-disciplinary, including nurses, social workers, and psychiatrists as part of the team. ACT programs are also envisioned to include peer members providing direct services who have utilized mental health services themselves (Phillips et al., 9 2001).

Studies of service user satisfaction with ACT have revealed they are generally satisfied with the service they receive; especially with the interpersonal aspects of care, persistence of the staff, supports for daily living, setting goals, personal growth, and community involvement (Leiphart \& Barnes, 曰 2005; Redko, Durbin, Wasylenki, \& Krupa, $\boldsymbol{\theta}$ 2004; Tschopp, Berven, \& Chan, $\boldsymbol{\theta}$ 2011).

\section{Methodology}

This study was conducted with the clients and clinicians of the Guelph ACT team in Southwestern Ontario in Canada. The study employed a qualitative research approach whereby we conducted individual interviews with consenting clients of the ACTT, and conducted a focus group and key informant interviews with the clinicians comprising the ACTT.

\section{Recruitment of client participants}

The ACTT social work clinicians agreed to conduct in-person meetings with all current ACTT clients who met the inclusion criteria to inform them about the study; scripts were provided to the social workers to guide this conversation and written information was given to the clients. Inclusion criteria 
were: 1) client had been placed on a CTO by the Guelph ACTT and continued to be on a CTO; 2) client had been placed on a CTO by the Guelph ACTT but was no longer on a CTO; 3 ) client had been placed on a CTO prior to being a client of the Guelph ACTT and either continued to be on a CTO or was no longer on a CTO; 4) the social worker assessed the client as capable of providing informed consent. The questions explored ACTT clients experience with CTOs, how they felt about it, circumstances that contributed to being on a CTO, and their experiences with CTOs while on it (See appendix 1). The questions did not change during the course of the interviews as the focus was to explore the experience of the client and their perception about CTOs.

Eighteen of the Guelph ACTT clients were eligible to participate, ${ }^{1}$ however, only 11 agreed to participate in the study. The interviews, conducted by a social work doctoral student with approximately about 20 years clinical practice experience, took place at the ACTT office in Guelph, Ontario, at a date and time of the clients' convenience. All but three participants consented to audio recording of the interviews, which were later transcribed. The interviewer took notes as the interview progressed for the three participants who did not consent to recording. These notes were later typed and entered into Nvivo, which was used for data analysis. The interviewer followed an interview guide with open-ended questions and planned prompts, and encouraged participants to talk openly and freely about their personal experiences. The interview guide was developed based on a review of the literature and discussions with the ACTT clinicians. Client participants were given a $\$ 25.00$ gift card to express appreciation for their time and contribution to the study. This research protocol received approval from both the Research Ethics Board at the authors' University and the Homewood Health Centre.

\section{Recruitment of clinician participants}


that invited them to participate in the focus group held at the ACTT office. All the clinicians participated in the study with the exception of the only social worker on the team, who was part of this study. The ACTT at this particular time did not have a psychologist on the team. Those who participated were mostly nurses and occupational therapists including the psychiatrist. The composition of clinicians at the time is a representation of a typical ACTT team in Ontario. The researchers utilized open-ended questions and planned prompts to elicit discussion. Two key informant interviews were conducted, one with the ACTT psychiatrist and the second with the Program Coordinator, guided by the same questions as for the focus group. These interviews were conducted by the researchers involved in the study and it lasted between an hour and an hour and a half. They were audio recorded and transcribed.

\section{Data analysis}

The analysis of the data was undertaken by the two researchers and the doctoral student. The analysis began with the creation of a coding framework that reflected the questions in the client interview guide. The responses to each question were coded and a thematic analysis followed (Braun \& Clarke, $\boldsymbol{\theta}$ 2006). We used an inductive approach (bottom-up) that endeavoured to stay close to the data and avoided imposing a theoretical framework where possible. We looked for patterns and themes across the responses to each question. A similar process was followed for the focus group and key informant interviews. NVivo software was used to facilitate the data analysis. Meetings between the research team members occurred to discuss the evolving themes from the patterns each was identifying. The researchers also discussed the consistency of the coding for accuracy. Separate summaries of the patterns and themes were created for the client interviews and for the clinician interviews. We then organized the findings per our original research questions. Those client participants who requested it were sent a copy of the summary of the patterns and 
themes, and invited to contact the researchers if they wished to comment on or add to the summary. Clinicians were sent summaries and encouraged to provide feedback.

\section{Description of client participants}

Of the eleven consenting client participants, five were female and six male. Their ages ranged from 27 to 66 years with a mean of 40.5 years. Nine of the participants identified their ethnic background as "white"; one said he or she was part "Native", while one stated he/she was born outside Canada but did not identify the country. Two participants stated they had graduated from secondary school, the remainder indicated they had not completed secondary school although three had received more education as adults. Eight of the participants were single, one was in a common-law relationship, and two were divorced. Several were receiving an Ontario Disability Support Pension. One had financial support from the Canada Pension Plan. Participants had been involved with the mental health system between 4 and 51 years with a mean of 16.3 years. The mode and median were 15 years.

Participants had been clients of the Guelph ACTT between four months and nine years. Most had been clients between four and seven years. Diagnosis was most commonly reported as bipolar disorder and three stated a diagnosis of schizophrenia. One reported a drug-induced psychosis. Two had been victims of violence.

Three participants reported they were previously on a CTO, and the remaining eight indicated they were currently on a CTO. For those who provided an estimate, the duration of the CTO ranged from three months to seven years, but some could not recall. Those who could recall the number of hospitalizations reported from three admissions to sixteen admissions.

\section{Description of clinician participants}


Six ACTT clinicians representing nursing and occupational

therapy disciplines consented to participate in the focus

group, and we interviewed two key informants, namely, the

ACTT psychiatrist and the Program Coordinator. The focus

group participants had worked on the team between two

and nine years with a mean of 7.4 years. The program

psychiatrist has been with the team for four years; the

Program Coordinator began working with the team seven

years ago and became the Coordinator three years ago.

\section{Findings}

The first objective of the study involved enhanced knowledge of the clients' experiences and perceptions regarding CTOs. Responses from participants revealed that perceptions were mixed.

\section{Diverse and changing feelings about placement on the CTO}

Most client participants described negative feelings regarding their CTO initially, such as anger, "livid" or "irritated". One participant felt it was unfair and s/he ${ }^{2}$ was treated like a "criminal" being punished. Another said it was like being "on a leash". One recalled being concerned about privacy and fear that her/his neighbours would find out about the CTO because of the presence of ACTT clinicians administering medications at her/his home. One participant felt s/he had no choice but to accept the CTO, and stated,

There's no sense in arguing it because they are going to get their lawyers and that...so it's just a waste of time getting all these people to come in.

A few participants also felt that the CTO was unnecessary and had not made any difference in their lives; they said they would have continued the prescribed medication and maintained similar relationships with family and friends without it. Another participant initially felt fearful because 
s/he did not fully understand what a CTO meant. However, s/he later concluded that it was "really good" because it meant she would have a psychiatrist and other services.

One participant who is now off the CTO, said the ACTT has helped her/him a lot and gave credit to friends who taught him/her to meditate and improve self-esteem. S/he thinks that without the support of the ACTT s/he would be at risk of relapse. Another liked the social aspects of being involved with the ACTT.

Three participants saw the benefit of the CTO, two were hesitant initially, and the remainder continued to have negative feelings towards it. One said that "it takes away your dignity" and s/he thought people should not be forced ... "It's like a knife, can be used two ways, good and bad". Later in the interview, this participant stated s/he recognized s/he needed help to live a healthy life.

\section{The importance of dignity}

Several participants referred to feeling a loss of respect or dignity when being on a CTO. One participant articulated

Dignity is a big thing for people, some say "it's (the (TO) just a piece of paper", but it's not, it's shameful - if a cop wanted to he could just pick you up, or if you missed your meds or looked "off" they could just pick you up - I've been hurt by a cop before. But it [CTO] also has benefits for people who need it.

This participant thought police should be better trained in mental health and be in plain clothing so service users are not embarrassed when approached by police.

Participants referred to the stigma associated with being labeled mentally ill, and some perceived that being placed on a CTO increased the stigma; one participant said, "I think when they do label you once, you're labeled for life." One participant, no longer on a CTO, declined to talk about 
involvement with the mental health system, as s/he felt it was painful "to go back to that part".

Analysis of the client interviews indicated that how the CTO was experienced was connected to how they perceived the trustworthiness of the Guelph ACT team clinicians and the helpfulness of the services provided The following quotes provide this context for understanding how some service users felt about the CTO.

Two participants talked about feeling more trust in the members of the ACTT as the years have gone by. Another said, "the longer I come here, the better I feel." Yet another participant explained what may be one of the reasons many clients were so positive about the team:

I don't think you can make them mad...No, they won't say, "listen here" ...if you get off the medication then you will be locked up'. ... They won't say that.

Several client participants talked about how much they liked individual ACTT clinicians and knew they were genuinely trying to help them. Some said the clinicians are "like friends".

Client participants discussed the following as helpful services provided by the ACTT: medication delivery; convenient office location; help with finding housing and obtaining subsidies; frequent home visits; help with grocery shopping or getting telephone service/repairs; help to get a health card, to get a driver's license and to get eyeglasses; transportation; help to better understand the mental illness they are dealing with; opportunities to participate in sporting events and groups such as cooking groups. Several participants said that relatively easy access to the team psychiatrist was appreciated, especially when she had adjusted medication in a helpful way.

With respect to the second study objective to increase 
knowledge of conditions and circumstances that contribute to decisions to employ a CTO, the eight ACTT clinician participants pointed out that according to the Ontario Mental Health Act, clients must meet specific criteria before being considered for a CTO. They also stressed that the use of a CTO is always a last resort. They referred to it as a "protective measure" and a "safety net."

One clinician (an occupational therapist) said,

I guess the people who end up on CTOs are the people who might have a more severe course of illness [they have had supports and] still can't follow the treatment plan.

The clinician stated that the decision to put ACTT clients on a CTO always involves "lots of discussion" within the team and with family members as well as with the client.

... the CTO - it typically is a last resort... [we say]

"we can prevent this hospitalization from happening but we might have to go to a CTO as a way to protect you and keep you safe in the community".

We heard that every Community Treatment Plan is tailored to the individual's strengths and needs. Other circumstances associated with the decision to employ a CTO was when people are "treatment resistant or fragile."

\section{Voluntary vs. involuntary in nature}

One of the issues that can lead to debate among team members is whether someone needs to be on a CTO "when they are going to be voluntary." This refers to a client who currently has insight and is capable of making treatment decisions, but has a history of, when feeling well, choosing to discontinue their prescribed medication and becoming ill again. Participants said that if the consensus is that issuing the CTO would benefit the client in some way, then they do so. A second issue that may lead to debate is whether or not 
a CTO should be discontinued. The debate might be around whether the CTO should continue as a "safety thing" or whether it should be removed to show the client how well s/he is doing and perhaps "spur them further in their recovery."

\section{Efforts to avoid enforcing the CTO}

The ACTT clinicians emphasized that they persevere in trying to find ways to work with a client when he or she is resisting following the Community Treatment Plan. One clinician (a nurse) talked about how the team works hard to avoid enforcing the CTO:

I think before [we issue a Form $47^{3}$ ]...and it is also educating (and reminding) the patient (sic) that you are on the CTO. We give them all the opportunity to come to the office or meet with the worker, wherever they would like to have their injection, within reason. We also work with families...So we sort of, try everything before we issue a Form 47.

Although for most clients on CTOs, Form 47s are rarely used, the team recognized that for some clients, their refusal to follow through with the conditions of the CTO is "the only control left in his/her life", and is therefore understood as a way some clients take what control they can.

The third objective of the study was to better understand both the rationale for and the effects of decisions to place clients on a CTO from the perspective of the ACTT clinicians.

It was clear that all clinician participants believed that it is in the best interest of certain ACTT clients to employ CTOs at times. Overall, they maintained that their clients have had a decrease in hospitalizations since being placed on a CTO. "Most of our patients, probably all of them had, if not no hospitalizations, a decrease in hospitalizations since they have been on a СTO." 
To better understand their thinking, we asked if it was possible to predict which clients would have positive outcomes following the use of a CTO. We heard that while it is very difficult to predict which clients will do well on a CTO, certain signs often predict better outcomes. Examples included 1) the client's insight that he or she has a mental illness requiring treatment, or at least recognition that following treatment recommendations helps to keep him or her out of hospital; 2) the client's medication controls symptoms well; 3 ) the client is able to increase independence with respect to taking medications; 4) the client makes changes in his or her lifestyle - particularly stopping the use of illegal substances 5) peer or family support for the CTO; and 6) the client's own efforts.

The clinicians stressed that the outcome of the decision to invoke a CTO is affected by many environmental and systemic factors including the combination of the CTO with the intensity of the ACTT's services, the cohesion and dynamics of the ACTT, and the quality of the relationships between the client and the team's clinicians.

\section{The importance of the combination of the CTO and assertive community treatment}

The close working relationship between clients and clinicians, and frequent contact that is possible for the ACTT, is, in their view, essential in supporting these individuals. The team members meet daily to discuss the clients with whom they work (not all are on CTO's), which provides the opportunity to discuss medication issues with the psychiatrist, as well as any problematic issues that require immediate attention. One clinician stated that she believes the ability of this ACTT to communicate well and intervene quickly is responsible for fewer and shorter hospital stays for their clients.

The clinicians explained that it is not only the combination of the ACTT services and the CTO that contributes to improvement in this group of clients. They stressed that the 
quality of the relationships that team members develop with clients plays an important role in client outcomes. They spoke of the challenges clients have faced in the past with multiple hospitalizations and numerous mental health professionals in and out of their lives, and how this influences their initial ability to develop trust in the ACT team professionals. They acknowledged that invoking a CTO often impairs the relationship with the client initially; however, in the long run it can lead to a stronger rapport:

But I don't think over time... [the CTO] remains as a barrier to having a strong therapeutic rapport with someone. If anything, I think it probably has allowed us to...maintain some stability for a longer period so you can get to know them better, you can meet their needs in many different ways so that you know, if they do have a period of increased symptoms or end up going to hospital again, you do have that to build on...(Nurse)

The clinicians agreed that a balance must be struck between the power and control inherent in the CTO while also encouraging clients to exercise autonomy in their personal goals related to living in the community. Others talked about how well they come to know their ACTT clients, and how, with developing trust, the clients share aspects of their lives apart from their illness. The clinicians acknowledged that developing trusting working relationships is also important because "...for some folks we are their only support."

\section{Professional boundaries}

The issue of professional boundaries was discussed in view of the close working relationships with clients; the clinicians very frequently work with clients in the clients' homes as well as in the community. The "relational" nature of the clinician/client relationship was stressed as the work is not solely focused on "treatment". The clinicians purposefully dress in casual clothing, so that when they are spending time 
in the community with their clients they do not "stick out like a sore thumb" as the person's "worker". With respect to attention to boundaries, one clinician put it this way:

Just based on the intensity of our service we are more apt to develop a closeness and a protective nature of our patients and it is something we have to monitor closely because we have to maintain that professional mental health worker/client relationship. Our clients, based on the fact that they see us sometimes twice a day every day seven days a week, they sometimes start to view us as friends and you know, some of them don't have family. They have ACTT, so it is - can be difficult to maintain that boundary and it is not always easy to see yourself slipping into it (Nurse).

\section{Discussion}

The objective involving enhanced knowledge of the perceptions of clients regarding CTOs has been met in that the data from this study of clients receiving a combination of ACT and placement on a CTO reveals themes similar to those reported in previous studies of clients' on CTOs, but not receiving ACT services (Brophy \& Ring, $\boldsymbol{\theta}$ 2004; Fahy et al., E 2013; Gibbs, Dawson, Ansley, \& Mullen, ש 2005; O’Reilly et al., $\boldsymbol{\theta}$ 2006). Clients in this study expressed a mixture of positive and negative thoughts and feelings about CTOs. Most clients described negative feelings initially, but a few recognized from the beginning that it might be helpful to them. After a period on the CTO, three clients were very sure it had been helpful and had improved their lives, whereas, several others acknowledged they felt less negative about the CTO than initially. However, some of those who recognized its benefit wished that when enforcement is necessary, it could be done in a less public and embarrassing way. 
Most client participants recognized that the ACTT clinicians

believed the CTO would benefit them and some felt that without a CTO their quality of life would be worse. Others felt CTOs were unnecessary. Like the previous study of clients on a CTO in Ontario (Schwartz et al., ש 2010), several participants in this study were concerned about the stigma associated with mental illness and loss of dignity while being on a CTO. These concerns led to the suggestion from one participant that instead of police officers, trained mental health staff should be designated to bring a client to the physician when a client has reneged on the treatment plan. This mirrors a concern expressed by family members in a Canadian study by O'Reilly et al. ( $\boldsymbol{\theta}$ 2006). Family members as well as clients are concerned about public perception and the stigma associated with police involvement. Police officers in plain clothes and unmarked cars would clearly be a welcome alternative.

The second and third objectives to enhance knowledge of conditions and circumstances that contribute to decisions to employ a CTO, and to better understand the rationale for and effects of decisions to place clients on a CTO have also been met. The clinician participants agreed that for clients with severe mental illness for whom nothing else has worked, CTOs are effective in preventing hospitalization, incarceration, and repeated psychotic episodes. They could describe several clients who have developed insight into their illness and/or recognized their need for treatment after a period on a CTO. The clinicians identified several conditions that seem to be associated with positive outcomes. These possible predictors of outcome could be the focus of future studies.

Several prior studies have reported that one advantage to being on a CTO is that it ensures clients get the services they need (Brophy \& Ring, $\boldsymbol{\theta}$ 2004; Gibbs et al., $\boldsymbol{\theta}$ 2005) and that the positive effects of CTOs may be more related to the intensity of services clients receive than the compulsory nature of the CTO (Churchill, Owen, Singh, \& Hotopf, $\boldsymbol{\theta}$ 2007; 
O’Brien, McKenna, \& Kydd, ש 2009). This study supports

these hypotheses and suggests that simultaneously

receiving services from an ACT Team while on a CTO may

provide clients with the ideal quantity and quality of

accessible services.

This ACT Team clinicians make a strong argument that the coercion inherent in a CTO is justified in view of the increased quality of life they have witnessed for many severely mentally ill clients. They argue that while the CTO does decrease client autonomy, skilled and dedicated clinicians, through patience and persistence, can develop a positive rapport with these difficult to engage clients; they can also successfully encourage them to identify personal goals toward which they and the client can work together. Data from both the clients and the clinicians support the idea that a well-functioning team of dedicated ACTT clinicians who prioritize positive collaborative relationships with their clients is an important context in which the use of CTOs can lead to good outcomes.

One change that the clinicians would welcome is a longer period between renewals of the CTO. A previous study also reported that a relative complained that the three-month duration of the CTO in Saskatchewan was too short because "the time of renewal of a CTO could reignite conflict" (O'Reilly et al., 2006, p. 522). One participant in that study acknowledged that it was very painful to talk about this history; another stressed concerns about privacy. Although this requires further study, we wonder if some clients might also prefer longer periods between renewals. On the other hand, such a change in the legislation may be unrealistic in view of the continuing controversy about CTOs and the need to balance individuals' rights to autonomy and selfdetermination with the need to reduce risk.

\section{Conclusion}


This study is limited by its reliance on clients and clinicians

from only one ACTT, which limits its generalizability. Another

limitation is the lack of family members' and substitute

decision makers' perspectives, and the lack of the

perspectives of social worker and psychologist clinicians

working in an ACTT. Relying only on qualitative data is

another limitation. Future studies should include

quantitative data regarding client participants'

hospitalizations and other expected outcomes before and

after the use of CTOs.

The findings support those of previous studies, and indicate the need for more research into questions about the optimal amount and type of community services required by clients on CTOs, as well as the characteristics of clients and the contextual conditions that predict a positive response to a CTO. We also need to know more about how to create and support teams of mental health professionals so they can do this important work effectively. Specifically, it will be important to study the most optimal composition for an interdisciplinary team to ensure team members have the appropriate education, training and resources; ongoing attention to caseloads will be important to ensure clients with lower levels of acuity receive the level of support they require.

In conclusion, despite concerns regarding coercion, lack of autonomy, and possible incongruity with a recovery-oriented approach, this study found that combining CTOs and ACT resulted in regular access to mental health supports, medication, housing, transportation, and overall improvement in the quality of life for clients. We hope a future study of CTOs and ACTTs in Canada and other jurisdictions will further explore the appropriateness of utilizing both outpatient approaches in supporting individuals with serious mental illness.

\section{Disclosure statement}


No potential conflict of interest was reported by the authors.

\section{Appendix 1}

Research Questions

The following were our specific research questions:

1. What are the experiences of ACTT clients who are or have previously been on a CTO? How do they perceive the decision to put them on a CTO in terms of appropriateness and helpfulness?

2. Are there differences in the experiences and perceptions of CTOs of Guelph ACTT clients who meet criteria for one of the following three groups: 1) those who came to the ACTT already on a CTO; 2) those who were placed on a CTO by the ACTT and 3) those ACTT clients who were previously on a CTO but are no longer under a CTO.

3. What conditions and circumstances contribute to the decision to put ACTT clients on a CTO from the perspectives of the ACTT clinicians ${ }^{4}$ ?

4. What are the Guelph ACTT clinicians' experiences and perceptions about the appropriateness and helpfulness of CTOs with ACT team clients?

5. How do the ACTT clinicians reconcile the use of CTOs with the "client-centered, recovery-oriented" approach to service delivery as articulated by the Ontario Program Standards for ACT teams (Government of Ontario, Ministry of Health and Long-term Care, 2005). The ACT Standards state, "Client empowerment, involvement, and choice are fundamental to the principles and operation of individualized, collaborative and effective ACT service delivery" (p. i).

\section{Notes}


1 Two clients were not capable of providing consent.

2 We are using "his/her" and "s/he" in this document to protect the identity of client participants.

3 This refers to the form that the physician completes when a client has failed to follow his or her obligations under the CTO; it authorizes the police to bring the client to the physician for an examination as to whether or not the client needs to be placed on a Form 1 (involuntary committal to hospital). If the psychiatrist does not deem that the client meets the criteria for a Form 1, the client will be offered ACTT services including medication support as well as other services if needed at the time of the assessment.

4.

\section{References}

1. Braun, V., \& Clarke, V. (2006). Using thematic analysis in psychology. Qualitative Research in Psychology, 3, 77-101. doi:10.1191/1478088706qp063oa[Taylor \& Francis Online] , [Google Scholar]

2. Brophy, L., \& Ring, D. (2004). The efficacy of involuntary treatment in the community: Consumer and service provider perspectives. Social Work in Mental Health, 2(2-3), 157-174. doi:10.1300/J200v02n02_10

[Taylor \& Francis Online], [Google Scholar]

3. Burns, T., Rugkasa, J., Molodynski, A., Dawson, J., Yeeles, K., Vazquez-Montes, M., ... Priebe, S. (2013). Community treatment orders for patients with psychosis (OCTET): A randomized controlled trial. Lancet, 381, 1627-1633. doi:10.1016/S0140-6736(13)60107-5 [Crossref], [PubMed], [Web of Science ${ }^{\circledR}$ ], [Google Scholar]

4. Churchill, R., Owen, G., Singh, S., \& Hotopf, M. (2007). 
International experiences of using community treatment

orders. London: Institute of Psychiatry. [Google Scholar]

5. Dye, S., Dannaram, S., Loynes, B., \& Dickenson, R. (2012). Supervised community treatment: 2 year follow-up study in Suffolk. The Psychiatrist, 36, 298-302.

doi:10.1192/pb.bp.111.036657[Crossref], [Google Scholar]

6. Fahy, G. M., Javaid, S., \& Best, J. (2013). Supervised community treatment: Patient perspectives in two Merseyside mental health teams. Mental Health Review Journal, 18(3), 157-164. doi:10.1108/MHRJ-11-2012-0030 [Crossref], [Google Scholar]

7. Felton, B. J., Barr, A., \& Clark, G. (2006). ACT team members' responses to training in recovery-oriented practices. Psychiatric Rehabilitation Journal, 30(2), 112-119. doi:10.2975/30.2006.112.119

[Crossref], [PubMed], [Web of Science ${ }^{\circledR}$ ], [Google Scholar]

8. Gault, I. (2009). Service-user and carer perspectives on compliance and compulsory treatment in community mental health services. Health and Social Care in the Community, 17(5), 504-513. doi:10.1111/j.1365-

2524.2009.00847.x

[Crossref], [PubMed], [Web of Science ${ }^{\circledR}$ ], [Google Scholar]

9. Gibbs, A., Dawson, J., Ansley, C., \& Mullen, R. (2005). How patients in New Zealand view community treatment orders. Journal of Mental Health, 14(4), 357-368.

doi:10.1080/09638230500229541[Taylor \& Francis Online] , [Google Scholar]

10. Government of Ontario, Ministry of Health and Long-Term Care. (2004). Ontario program standards for ACT teams (2nd ed.). (updated January 2005). Retrieved April 6, 2014, from http://ontarioacttassociation.com/on-act-standards/ [Google Scholar] 
11. Gray, J. E., \& O’Reilly, R. L. (2005). Canadian compulsory community treatment laws: Recent reforms. International Journal of Law and Psychiatry, 28, 13-22.

doi:10.1016/j.ijlp.2004.12.002

[Crossref], [PubMed], [Web of Science ${ }^{\circledR}$ ], [Google Scholar]

12. Horgan, S. A. (2000). The lived experience of people receiving assertive community treatment: A phenomenological study (Unpublished masters thesis). Wilfrid Laurier University, Waterloo, ON. [Google Scholar]

13. Kidd, S. A., George, L., O'Connell, M., Sylverstre, J., Kirkpatrick, H., Browne, G., ... Davidson, L. (2011). Recovery-oriented service provision and clinical outcomes in assertive community treatment. Psychiatric Rehabilitation Journal, 34(3), 194-201. doi:10.2975/34.3.2011.194.201 [Crossref], [PubMed], [Web of Science ${ }^{\circledR}$ ], [Google Scholar]

14. Kisely, S., Preston, N., Xiao, J., Lawrence, D., Louise, S., Crowe, E., \& Segal, S. (2013). An eleven-year evaluation of the effect of community treatment orders on changes in mental health service use. Journal of Psychiatric Research, 47, 650-656. doi:10.1016/j.jpsychires.2013.01.010 [Crossref], [PubMed], [Web of Science $\left.{ }^{\circledR}\right]$, [Google Scholar]

15. Kisely, S. R., \& Campbell, L. A. (2014). Compulsory community and involuntary outpatient treatment for people with severe mental disorders. Cochrane Database of Systematic Reviews 2014, (Issue 12).

doi:10.1002/14651858.CD004408.pub4/epdf/abstract [Crossref], [Google Scholar]

16. Krupa, T., Eastabrook, S., Beattie, P., Carriere, R., Mcintyre, D., \& Woodman, R. (2004). Challenges by service providers in the delivery of assertive community treatment. Canadian Journal of Community Mental Health, 23(1), 115-127. doi:10.7870/cjcmh-2004-0008 
[Crossref], [PubMed], [Google Scholar]

17. Krupa, T., Eastabrook, S., Hern, L., Lee, D., North, R., Percy, K., ... Wing, G. (2005). How do people who receive assertive community treatment experience this service? Psychiatric Rehabilitation Journal, 29(1), 18-24.

doi:10.2975/29.2005.18.24

[Crossref], [PubMed], [Web of Science ${ }^{\circledR}$ ], [Google Scholar]

18. Leiphart, L. R., \& Barnes, M. G. (2005). The client experience of assertive community treatment: $A$ qualitative study. Psychiatric Rehabilitation Journal, 28(4), 395-397. doi:10.2975/28.2005.395.397 [Crossref], [PubMed], [Web of Science ${ }^{\circledR}$ ], [Google Scholar]

19. Mfoafo-M'Carthy, M., \& Williams, C. (2010). Coercion and community treatment orders (CTOs): One step forward, two steps back? Canadian Journal of Community Mental Health, 29(1), 69-80. doi:10.7870/cjcmh-2010-0006 [Crossref], [Google Scholar]

20. Nakhost, A., Perry, J. C., \& Frank, D. (2012). Assessing the outcome of compulsory treatment orders on management of psychiatric patients at 2 McGill University-associated hospitals. The Canadian Journal of Psychiatry, 57(6), 359-365. doi:10.1177/070674371205700605 [Crossref], [PubMed], [Web of Science ${ }^{\circledR}$ ], [Google Scholar]

21. O'Brien, A., Farrell, S. J., \& Faulkner, S. (2009). Community treatment orders: Beyond hospital utilization rates examining the association of community treatment orders with community engagement and supportive housing. Community Mental Health Journal, 45, 415-419. doi:10.1007/s10597-009-9203-x [Crossref], [PubMed], [Web of Science ${ }^{\circledR}$ ], [Google Scholar]

22. O'Brien, A. J., McKenna, B. G., \& Kydd, R. R. (2009). Compulsory community mental health treatment: 
Literature review. International Journal of Nursing Studies, 46, 1245-1255. doi:10.1016/j.jinurstu.2009.02.006 [Crossref], [PubMed], [Web of Science ${ }^{\circledR}$ ], [Google Scholar]

23. O'Reilly, R. L., Brooks, S. A., Chaimowitz, G. A., Neilson, G. E., Carr, P. E., Zikos, E., ... Beck, P. R. (2009). Mandatory outpatient treatment: position paper. Retrieved from Canadian Psychiatric Association website https://ww1.cpaapc.org/Publications/Position_Papers/mandatory.asp [Google Scholar]

24. O’Reilly, R. L., Keegan, D. L., Corring, D., Shrikhande, S., \& Natarajan, D. (2006). A qualitative analysis of the use of community treatment orders in Saskatchewan. International Journal of Law and Psychiatry, 29, 516-524. doi:10.1016/j.ijlp.2006.06.001 [Crossref], [PubMed], [Web of Science ${ }^{\circledR}$ ], [Google Scholar]

25. O'Reilly, R. L., Keegan, D. L., \& Elias, J. W. (2000). A survey of the use of community treatment orders by psychiatrists in Saskatchewan. Canadian Journal of Psychiatry, 45, 79-81. [Crossref], [PubMed], [Web of Science ${ }^{\circledR}$ ], [Google Scholar]

26. Ontario Mental Health Act R.S.O. (1990, c. M-7). Ministry of health. Retrieved July 13, 2015, from http://www.ontario.ca/laws/statute/90m07\#BK37 [Google Scholar]

27. Phillips, S. D., Burns, B. J., Edgar, E. R., Mueser, K. T., Linkins, K. W., Rosenheck, R. A., ... McDonel Herr, E. C. (2001). Moving assertive community treatment into standard practice. Psychiatric Services, 52(6), 771-779. doi:10.1176/appi.ps.52.6.771

[Crossref], [PubMed], [Web of Science ${ }^{\circledR}$ ], [Google Scholar]

28. Priebe, S., Watts, J., Chase, M., \& Matanov, A. (2005). Processes of engagement and disengagement in assertive outreach patients: Qualitative study. The British Journal of 
Psychiatry, 187, 438-443. doi:10.1192/bjp.187.5.438

[Crossref], [PubMed], [Web of Science ${ }^{\circledR}$ ], [Google Scholar]

29. Redko, C., Durbin, J., Wasylenki, D., \& Krupa, T. (2004).

Participant perspectives on satisfaction with assertive community treatment. Psychiatric Rehabilitation Journal, 27(3), 283-286. doi:10.2975/27.2004.283.286

[Crossref], [PubMed], [Web of Science ${ }^{\circledR}$ ], [Google Scholar]

30. Ridley, J., \& Hunter, S. (2013). Subjective experiences of compulsory treatment from a qualitative study of early implementation of the Mental Health (Care \& Treatment) (Scotland) Act 2003. Health and Social Care in the Community, 21(5), 509-518. doi:10.1111/hsc.12041 [Crossref], [PubMed], [Web of Science ${ }^{\circledR}$ ], [Google Scholar]

31. Salyers, M. P., Stull, L. G., Rollins, A. L., \& Hopper, K. (2011). The work of recovery on two assertive community treatment teams. Administration and Policy in Mental Health/Mental Health Services Research, 38(3), 169-180. doi:10.1007/s10488-010-0311-2 [Crossref], [PubMed], [Web of Science ${ }^{\circledR}$ ], [Google Scholar]

32. Schwartz, K., O'Brian, A. M., Morel, V., Armstrong, M., Fleming, C., \& Moore, P. (2010). Community treatment orders: The service user speaks exploring the lived experience of community treatment orders. International Journal of Psychosocial Rehabilitation, 15(1), 39-50. Retrieved July 8, 2015, from, http://www.psychosocial.com/IJPR_15/Community_ServiceOrders_Schwartz.html [Google Scholar]

33. Swartz, M. S., Wilder, C. M., Swanson, J. W., Van Dorn, R. A., Robinson, P. C., Steadman, H. J., ... Monahan, J. (2010). Assessing outcomes for consumers in New York's assisted outpatient treatment program. Psychiatric Services, 61(10), 976-981. doi:10.1176/appi.ps.61.10.976 [Crossref], [PubMed], [Web of Science ${ }^{\circledR}$ ], [Google Scholar] 
34. Trueman, S. (2003). Community treatment orders and Nova Scotia - The least restrictive alternative? Health Law Journal, 11, 1-33.[PubMed], [Google Scholar]

35. Tschopp, M. K., Berven, N. L., \& Chan, F. (2011). Consumer perspectives of assertive community treatment interventions. Community Mental Health Journal, 47, 408-414. doi:10.1007/s10597-010-9335-z [Crossref], [PubMed], [Web of Science ${ }^{\circledR}$ ], [Google Scholar]

36. Watts, J., \& Priebe, S. (2002). A phenomenological account of users' experiences of assertive community treatment. Bioethics, 16(5), 439-454. doi:10.1111/biot.2002.16.issue-5 [Crossref], [PubMed], [Web of Science ${ }^{\circledR}$ ], [Google Scholar]

\section{Additional information}

\section{Funding}

This work was supported by the Mitacs [IT04831];Homewood Health Centr's Research Institute [000000] 


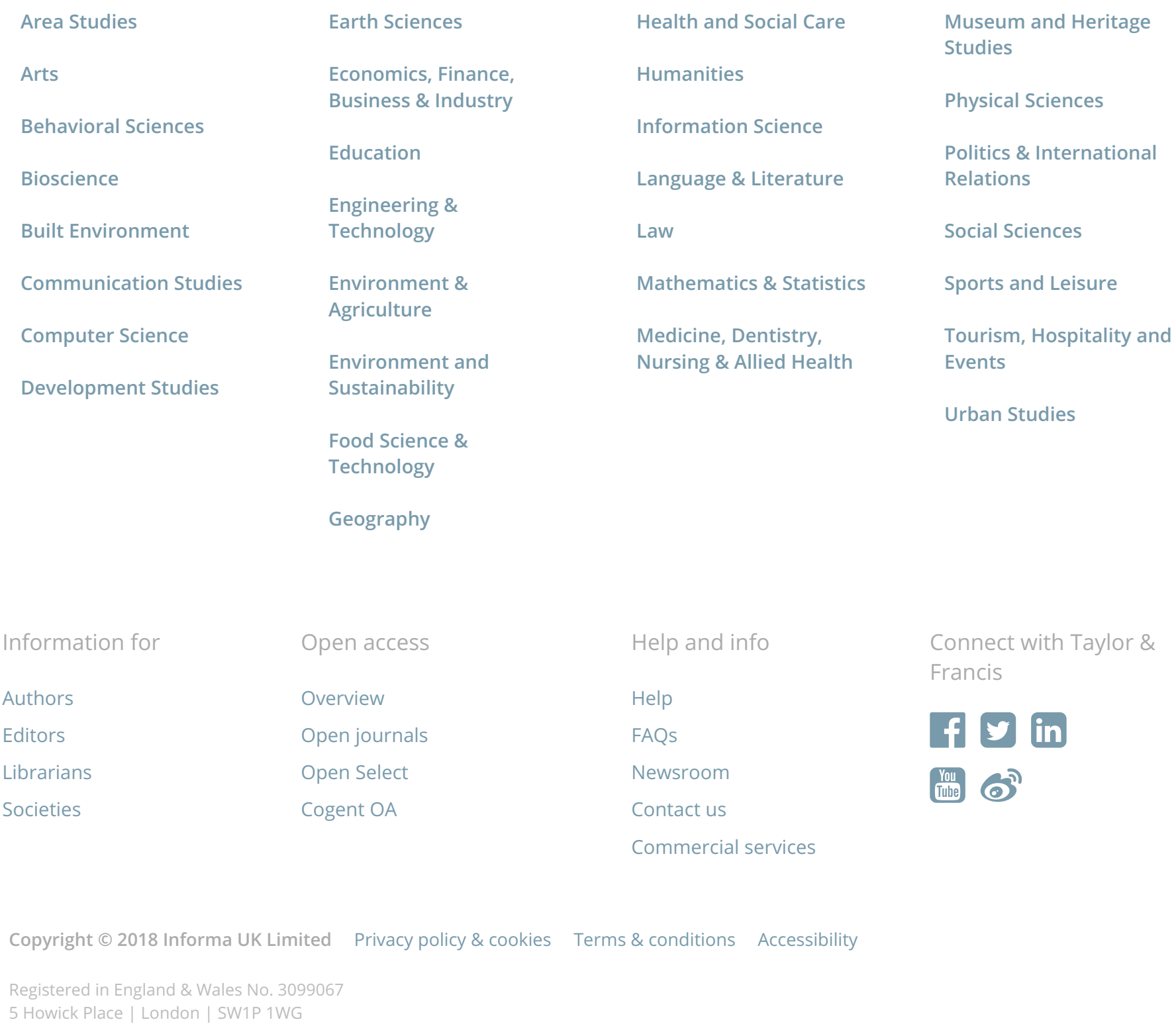

